—Supporting Information-

$\begin{array}{lllr}\text { Superhydrophobic Foams } & \text { with } & \text { Chemical- } & \text { and } \\ \text { Mechanical-Damage-Healing } & \text { Abilities } & \text { Enabled } & \text { by } \\ \text { Self-Healing Polymers } & & & \end{array}$

Yonghao Fu, Fuchang Xu, Dehui Weng, Xiang Li, Yang Li* and Junqi Sun

State Key Laboratory of Supramolecular Structure and Materials, College of Chemistry, Jilin University, Changchun 130012, PR China.

*E-mail: yanglichem@jlu.edu.cn 


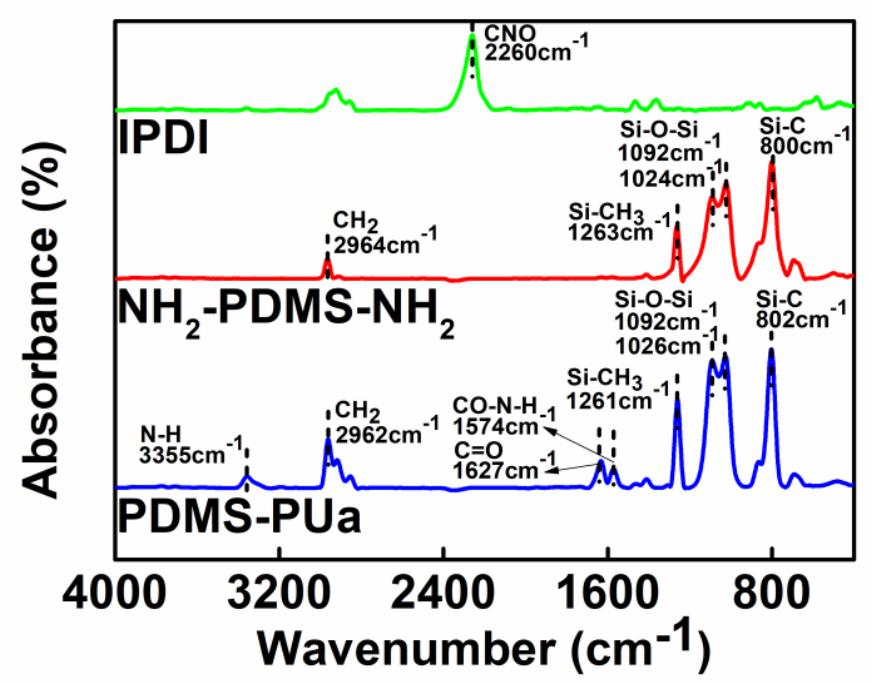

Figure S1. FTIR spectra of IPDI, $\mathrm{NH}_{2}-\mathrm{PDMS}-\mathrm{NH}_{2}$ and PDMS-PUa.

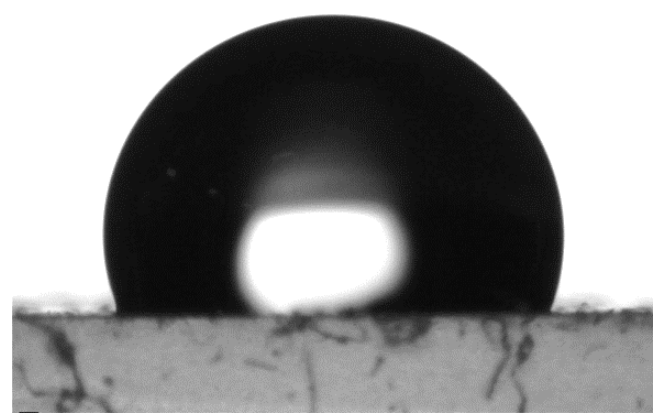

Figure S2. Shape of water droplet $(4 \mu \mathrm{L})$ on the PDMS-PUa film.

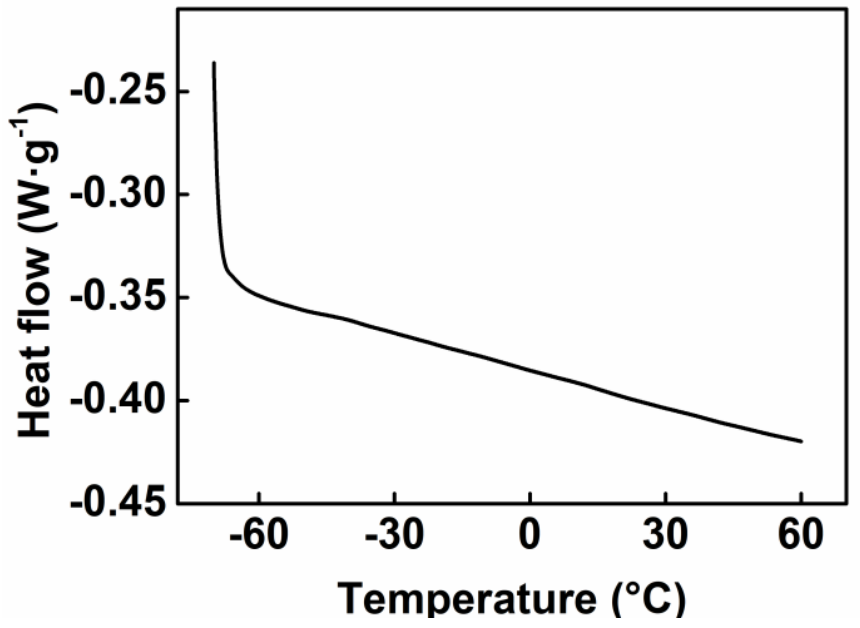

Figure S3. Differential scanning calorimetry (DSC) curve of PDMS-PUa. The $T_{\mathrm{g}}$ must be lower than $-70{ }^{\circ} \mathrm{C}$ as there is no endothermal signal in the curve. $-70{ }^{\circ} \mathrm{C}$ is the lowest measurable temperature of our instrument. 


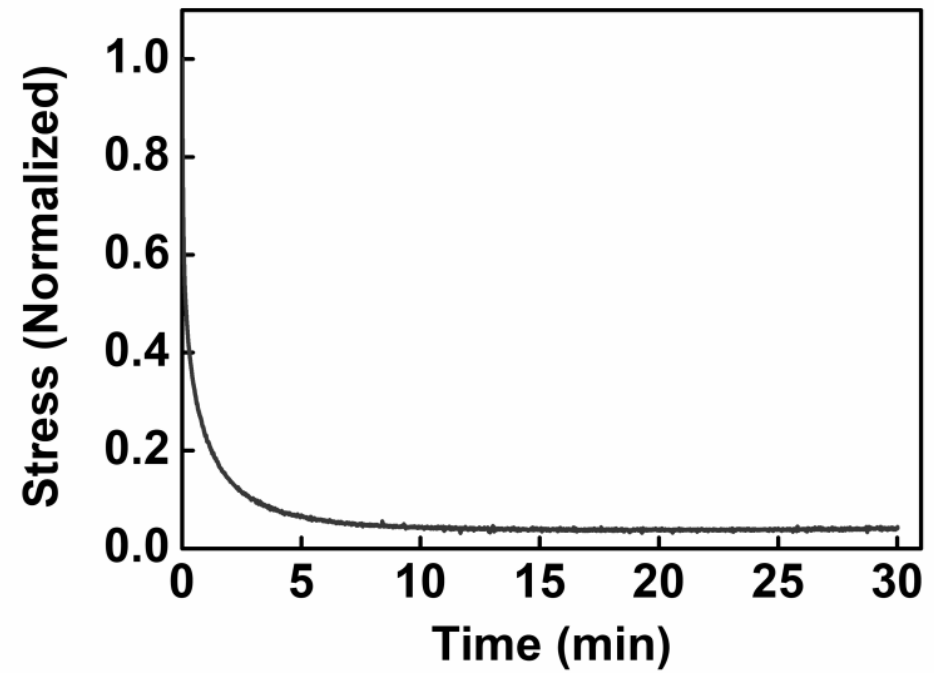

Figure S4. Stress-strain curve of the PDMS-PUa film. The film was stretched to a strain of $3 \%$ at $25{ }^{\circ} \mathrm{C}$ and then maintained for $30 \mathrm{~min}$. The relaxation in stress was recorded as a function of time. After $30 \mathrm{~min}$, the residual stress ratio of the PDMS-PUa film was $4 \%$.

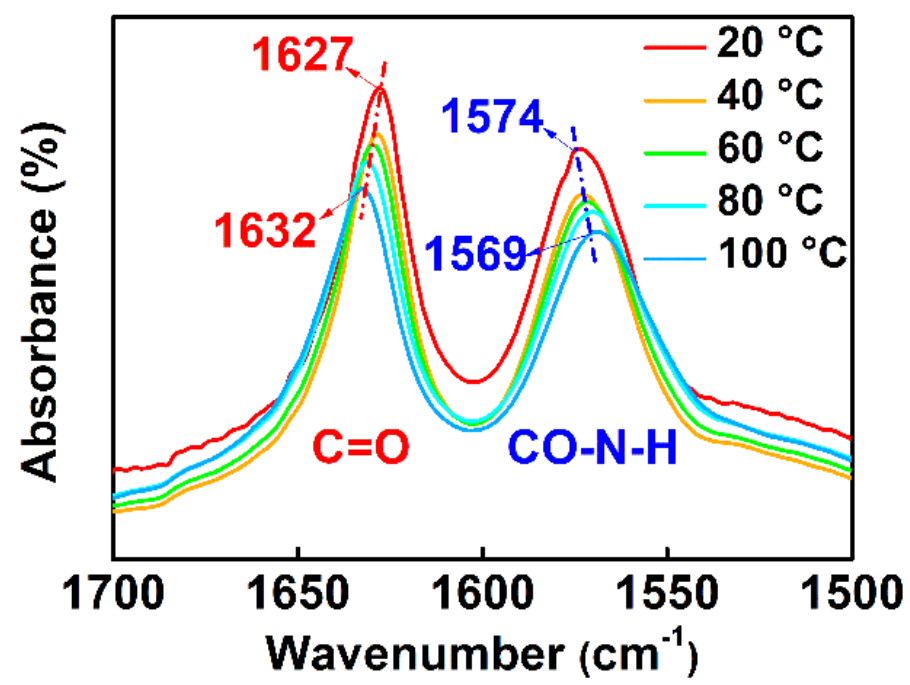

Figure S5. Temperature dependent IR spectra of PDMS-PUa at $20^{\circ} \mathrm{C}, 40{ }^{\circ} \mathrm{C}, 60^{\circ} \mathrm{C}$, $80^{\circ} \mathrm{C}$, and $100^{\circ} \mathrm{C}$, respectively. 


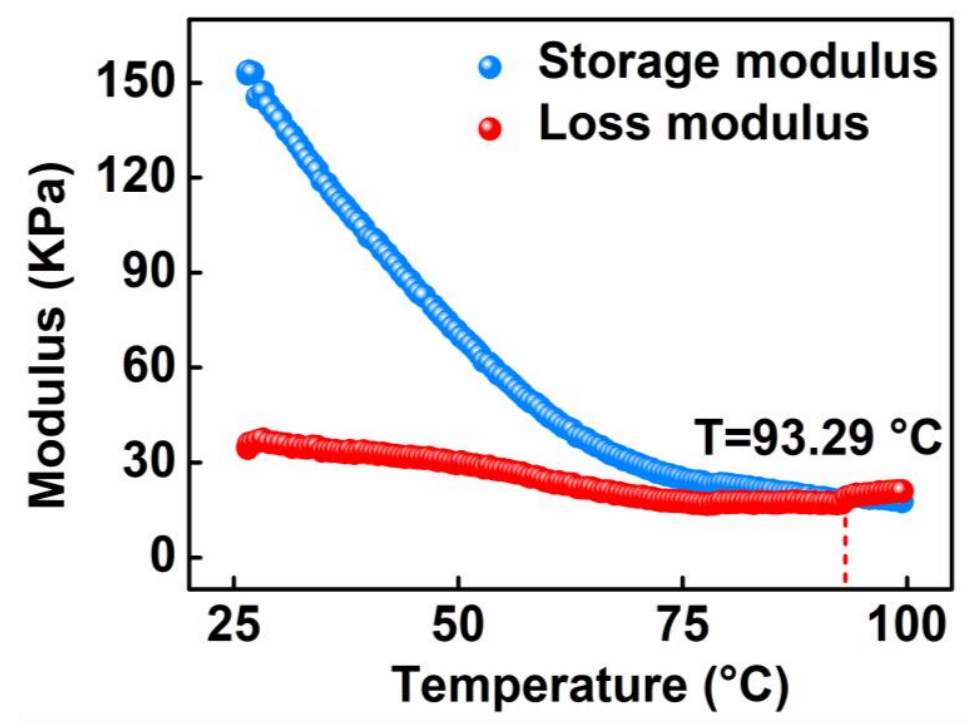

Figure S6. Temperature dependent rheology spectrum of PDMS-PUa in the temperature range of 25 to $100{ }^{\circ} \mathrm{C}$.

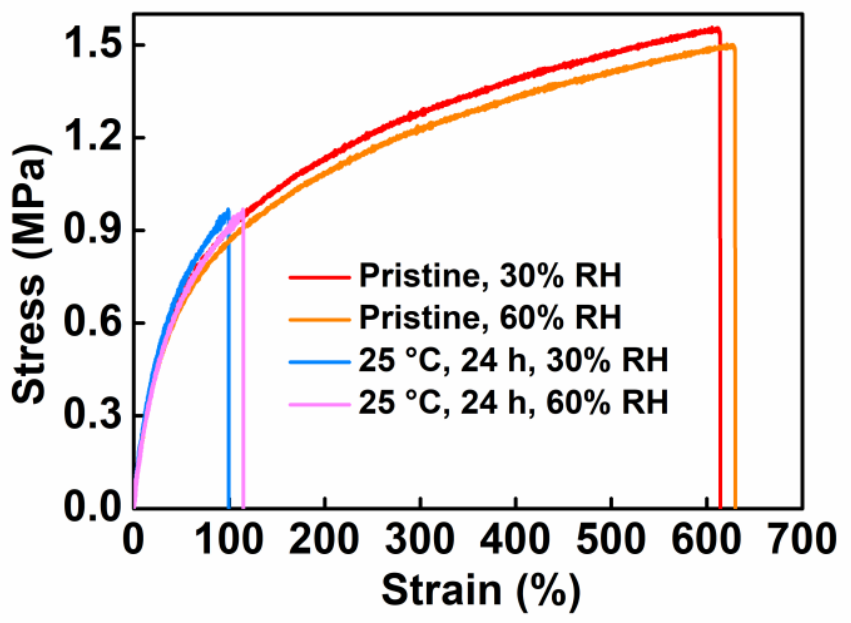

Figure S7. Stress-strain curves of the pristine PDMS-PUa films at $30 \% \mathrm{RH}$ and $60 \%$ $\mathrm{RH}$, and the cut films after healing at $25^{\circ} \mathrm{C}$ for $24 \mathrm{~h}(30 \% \mathrm{RH}$ and $60 \% \mathrm{RH})$.

To investigate the influence of moisture on the stretchability of the PDMS-PUa, a piece of PDMS-PUa film was stored in a $60 \%$ relative humidity $(\mathrm{RH})$ environment for $1 \mathrm{~d}$ and its stretchability was tested at $60 \% \mathrm{RH}$. As shown in Figure S7, the stretchability of the PDMS-PUa film at $30 \% \mathrm{RH}$ was similar to that of the film at $60 \%$ RH. Moreover, a piece of PDMS-PUa film was cut in half and healed at $25{ }^{\circ} \mathrm{C}$ and $60 \% \mathrm{RH}$. After healing for $24 \mathrm{~h}$, the healing efficiency of the film was $63.7 \pm 3.2 \%$, which was similar to that of the film healed at $30 \% \mathrm{RH}(62.3 \pm 3.7 \%)$. All these results indicate that the PDMS-PUa has a good hydrolytic stability, which can be attributed to the hydrophobicity of the PDMS segments. 
(a)

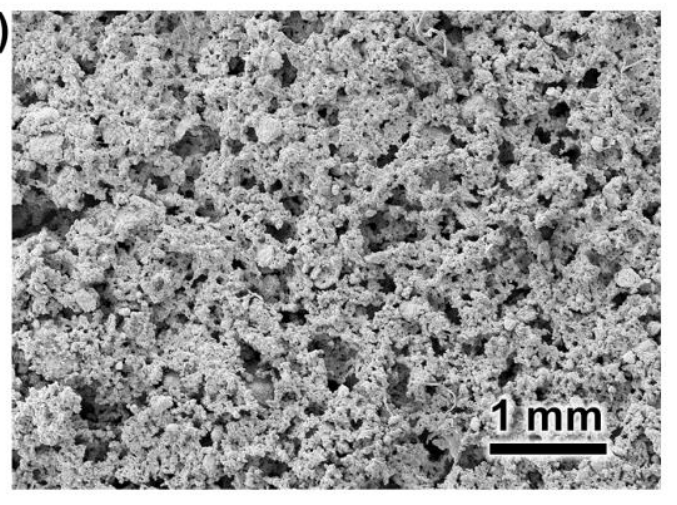

(b)

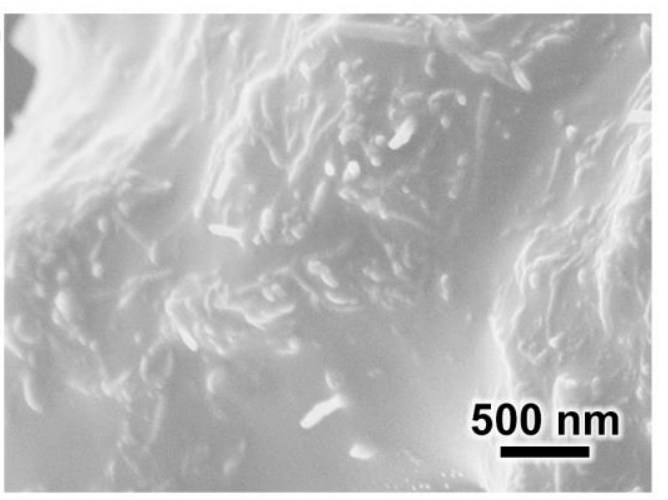

Figure S8. (a) SEM image of the internal structure of the MCNTs/PDMS-PUa foam. (b) Magnified SEM image of the surface of the skeleton in (a).

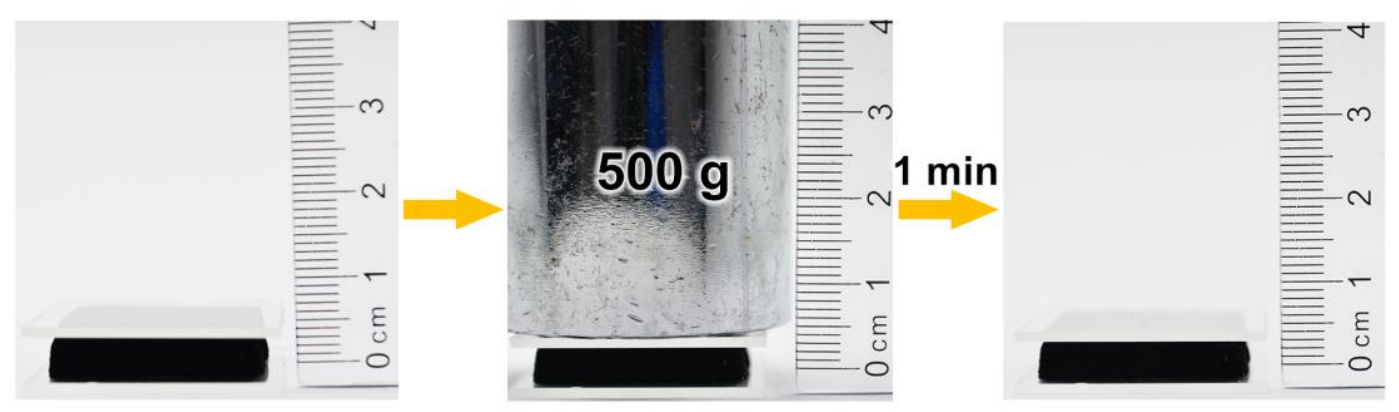

Figure S9. Photo images showing the compression resistance of the MCNTs/PDMS-PUa foam.

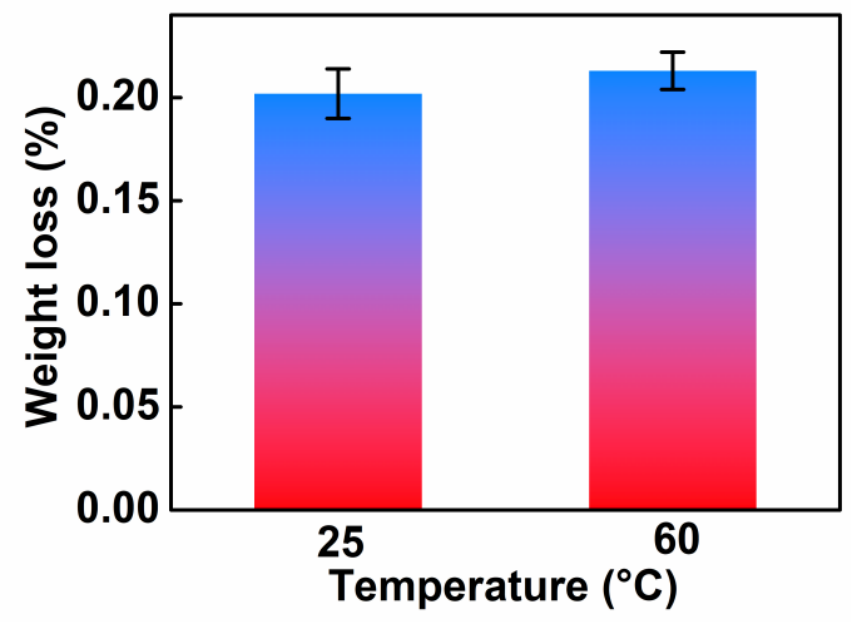

Figure S10. Weight loss of the MCNTs/PDMS-PUa foams after being rubbed with a piece of sandpaper at $25{ }^{\circ} \mathrm{C}$ and $60{ }^{\circ} \mathrm{C}$, respectively. 
To study whether the MCNTs/PDMS-PUa foam is more susceptible to damage at an elevated temperature, a piece of MCNTs/PDMS-PUa foam was stored at $60{ }^{\circ} \mathrm{C}$ for 24 $\mathrm{h}$ and then was manually rubbed with a piece of 2000-grit sandpaper for 10 strokes. The weight loss of the foam was calculated by the following equation: Weight loss (\%) $=\left(m_{0}-m_{1}\right) / m_{0} \times 100 \%$, where $m_{0}$ and $m_{1}$ are the weights of the foam before and after rubbing.

Table S1. Summary of the Mechanical Properties and Wettability of the MCNTs/PDMS-PUa Foams with Different Salt Content in Their Raw Materials

\begin{tabular}{ccccc}
\hline $\begin{array}{c}\text { mass ratio } \\
(\mathrm{PDMS}-\mathrm{PUa}: \mathrm{MCNT}: \mathrm{NaCl})\end{array}$ & $\begin{array}{c}\text { static contact angle } \\
\left({ }^{\circ}\right)\end{array}$ & $\begin{array}{c}\text { sliding angle } \\
\left({ }^{\circ}\right)\end{array}$ & $\begin{array}{c}\text { stress } \\
(\mathrm{MPa})\end{array}$ & $\begin{array}{c}\text { strain } \\
(\%)\end{array}$ \\
\hline $1: 0.3: 3$ & $154.6 \pm 0.5$ & $5.0 \pm 0.6$ & 0.039 & 18.03 \\
$1: 0.3: 5$ & $154.2 \pm 0.6$ & $5.1 \pm 0.7$ & 0.028 & 11.15 \\
$1: 0.3: 7$ & $154.2 \pm 0.4$ & $5.1 \pm 0.5$ & 0.018 & 10.30 \\
\hline
\end{tabular}

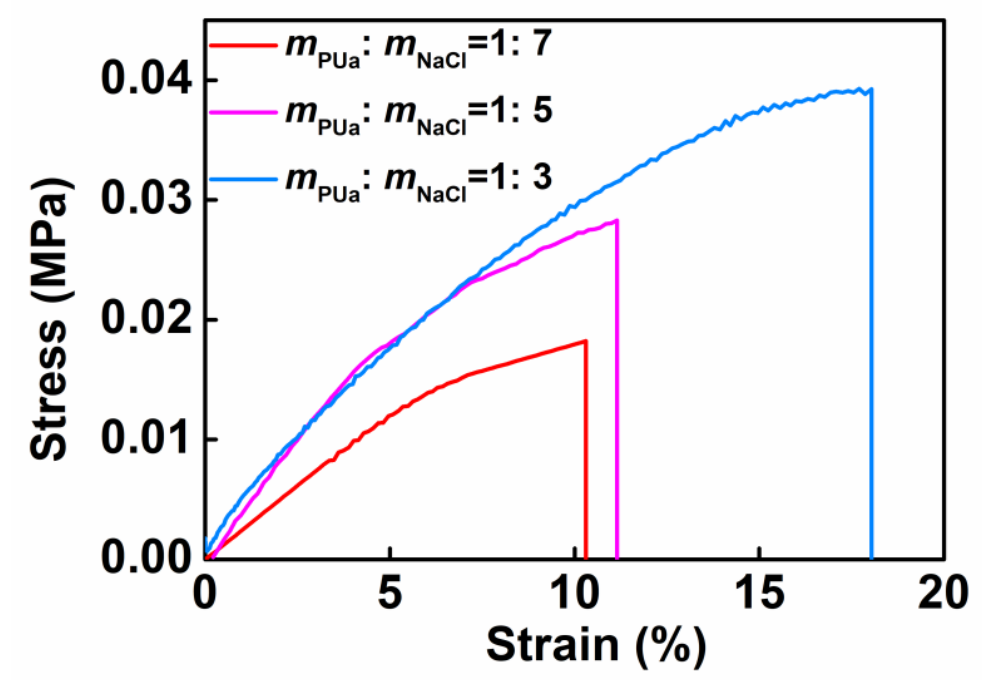

Figure S11. Stress-strain curves of the MCNTs/PDMS-PUa foams with different salt content in their raw materials. The stretching speed was $50 \mathrm{~mm} \mathrm{~min}^{-1}$. 
Table S2. Summary of the Mechanical Properties and Wettability of the MCNTs/PDMS-PUa Foams with Different MCNT Content in Their Raw Materials

\begin{tabular}{ccccc}
\hline $\begin{array}{c}\text { mass ratio } \\
\text { (PDMS-PUa: MCNT: } \mathrm{NaCl})\end{array}$ & $\begin{array}{c}\text { contact angle } \\
\left({ }^{\circ}\right)\end{array}$ & $\begin{array}{c}\text { sliding angle } \\
\left({ }^{\circ}\right)\end{array}$ & $\begin{array}{c}\text { stress } \\
(\mathrm{MPa})\end{array}$ & $\begin{array}{c}\text { strain } \\
(\%)\end{array}$ \\
\hline 1: $0.1: 5$ & $144.2 \pm 0.3$ & $25.5 \pm 1.5$ & 0.134 & 31.63 \\
1: $0.2: 5$ & $153.2 \pm 0.7$ & $5.6 \pm 1.2$ & 0.094 & 17.02 \\
1: $0.3: 5$ & $154.2 \pm 0.6$ & $5.1 \pm 0.7$ & 0.032 & 11.54 \\
\hline
\end{tabular}

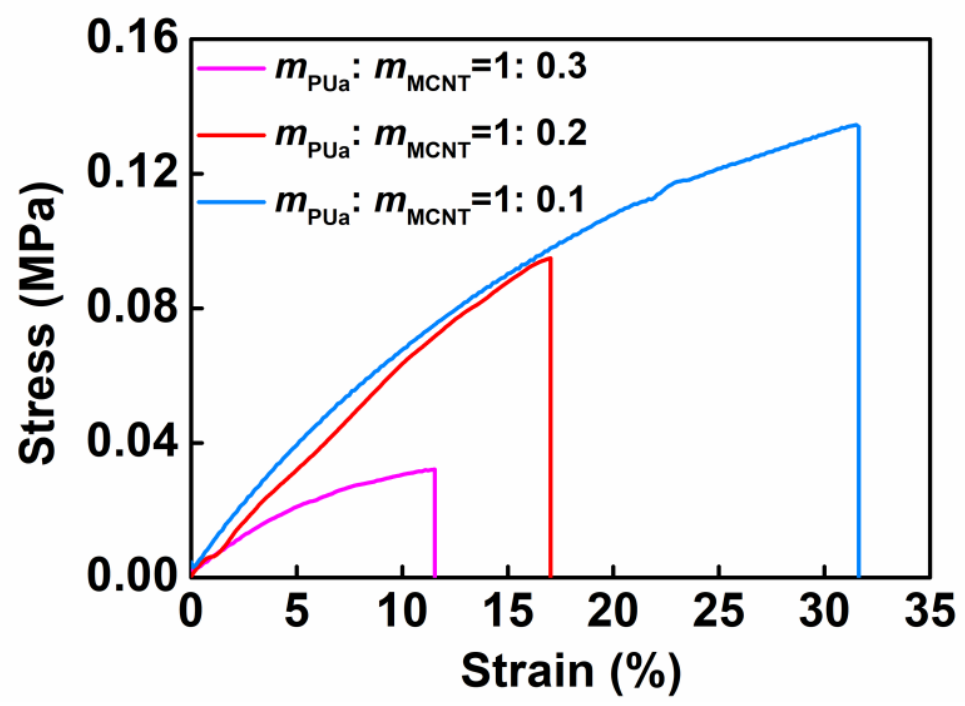

Figure S12. Stress-strain curves of the MCNTs/PDMS-PUa foams with different MCNT content in their raw materials. The stretching speed was $50 \mathrm{~mm} \mathrm{~min}^{-1}$.
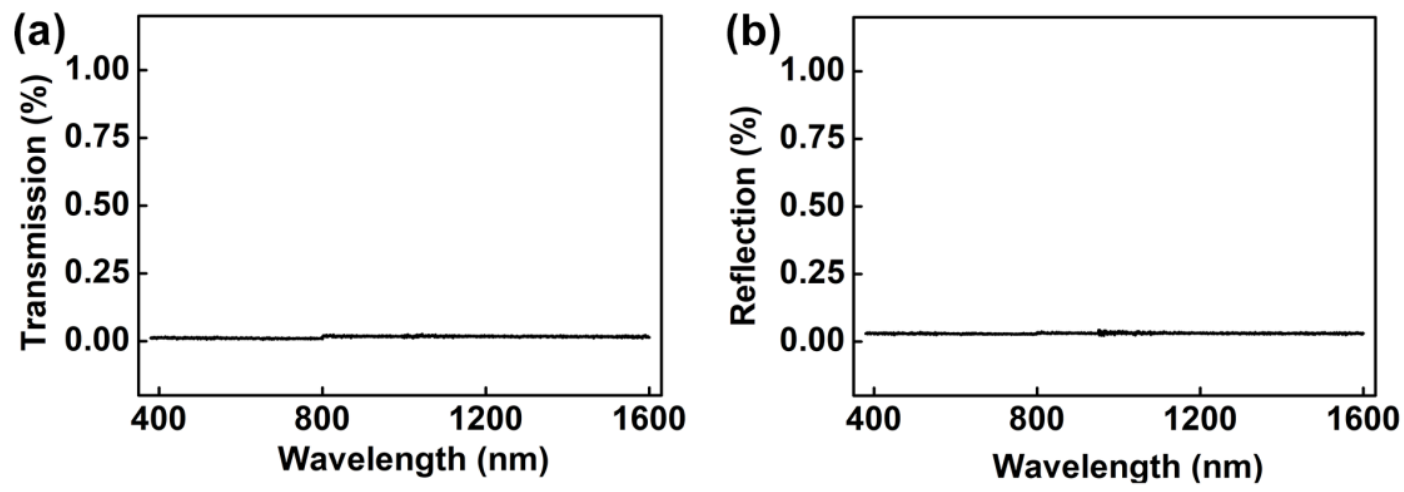

Figure S13. The average transmittances (a) and reflections (b) of the MCNTs/PDMS-PUa foams within wavelengths ranging from $380 \mathrm{~nm}$ to $1600 \mathrm{~nm}$. 


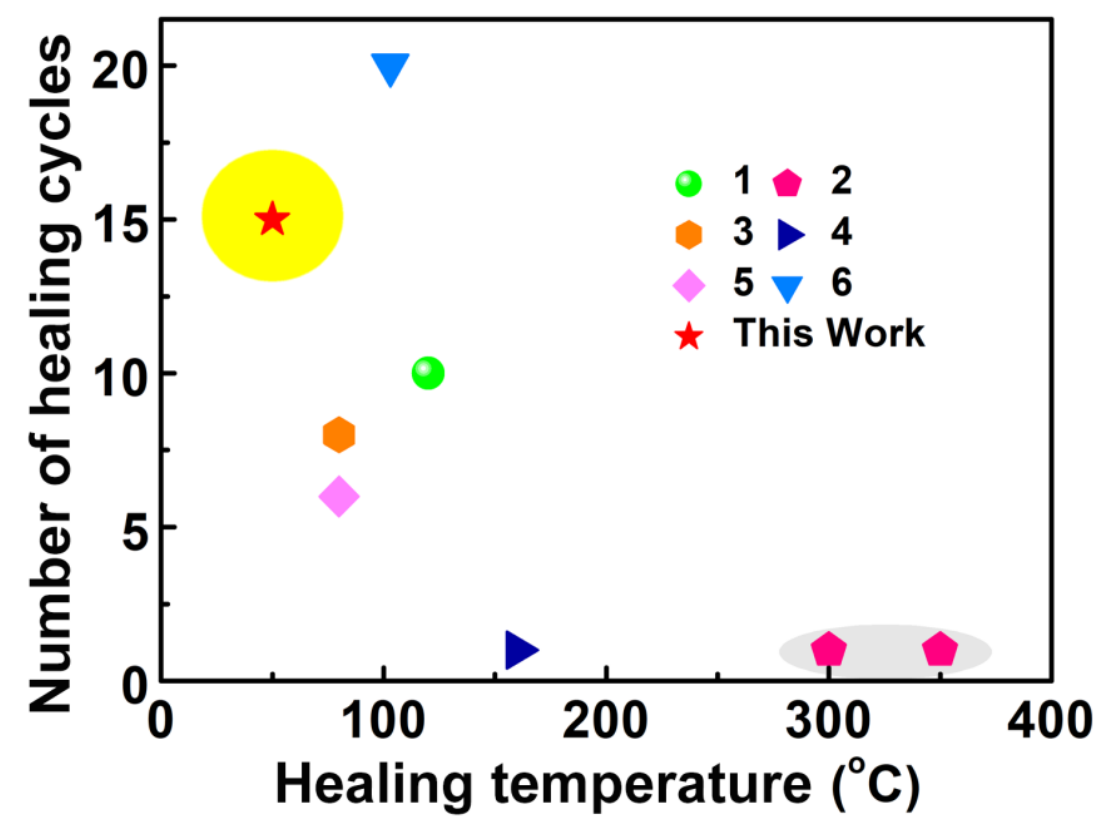

Figure S14. Ashby plot of the number of healing cycles against healing temperature of the MCNTs/PDMS-PUa foam and various hydrophobic-polymer-based self-healing superhydrophobic materials capable of healing chemical damage. ${ }^{1-6}$

(a)

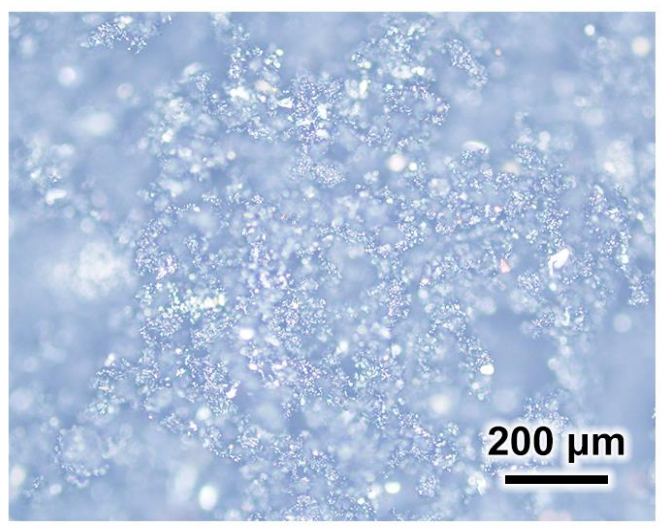

(b)

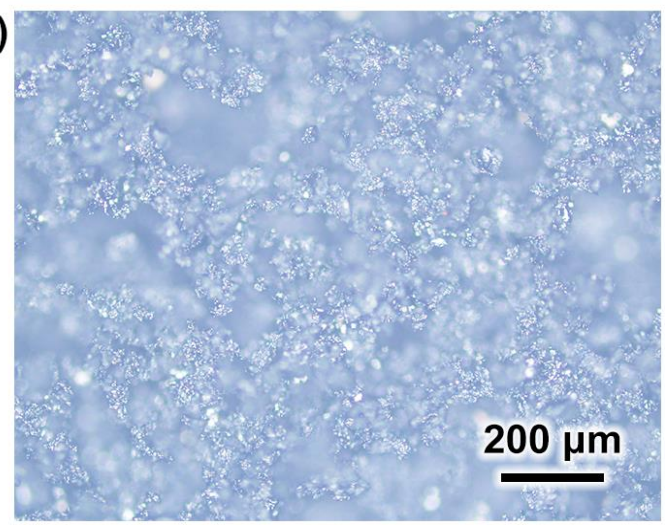

Figure S15. Optical microscope images of the MCNTs/PDMS-PUa foam (a) before and (b) after being rubbed with sandpaper. 


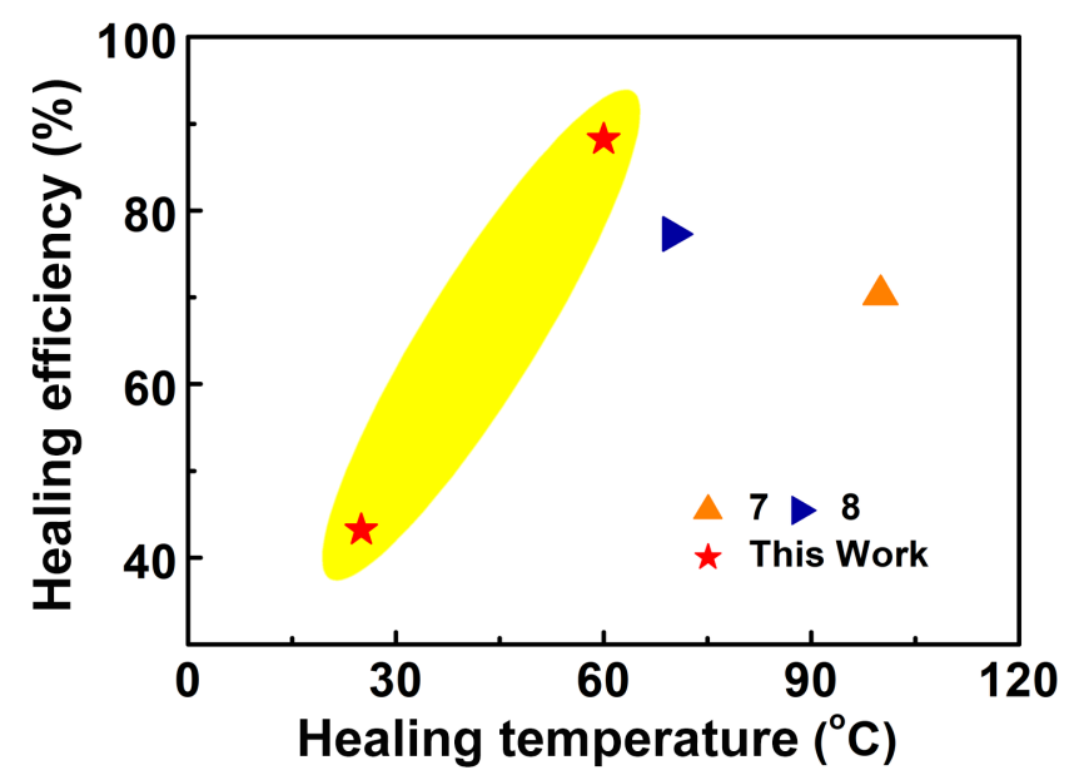

Figure S16. Ashby plot of the healing efficiency against healing temperature of the MCNTs/PDMS-PUa foam and various superhydrophobic bulk materials capable of healing mechanical damage.,

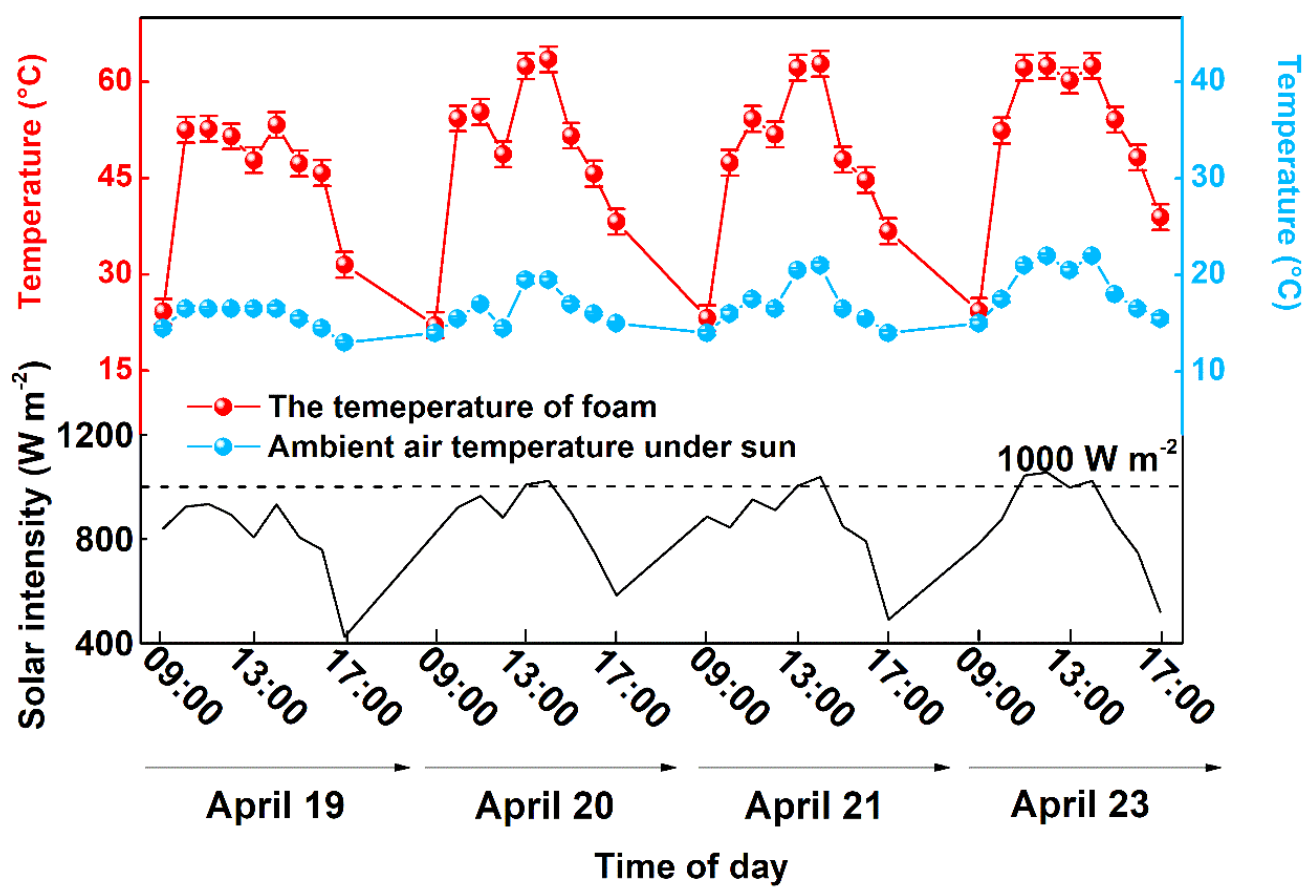

Figure S17. The solar intensity, ambient temperature, and temperature changes of the MCNTs/PDMS-PUa foam under the sun at Jilin University. 
(a)

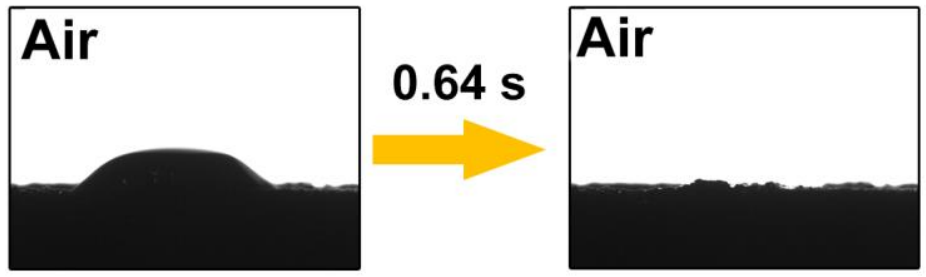

(b)

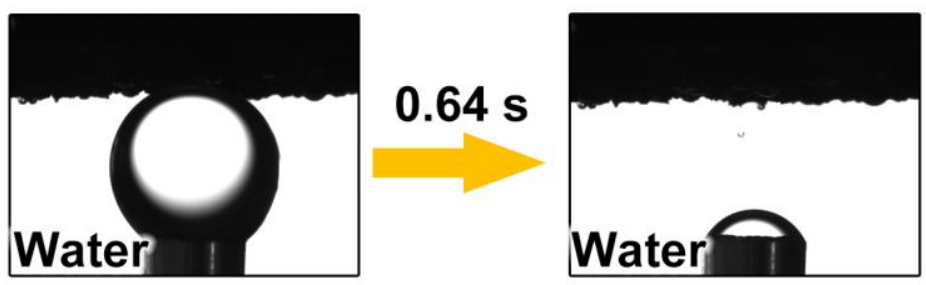

Figure S18. Images showing hexadecane droplets $(4 \mu \mathrm{L})$ being absorbed by the MCNTs/PDMS-PUa foams placed in (a) air and (b) water.

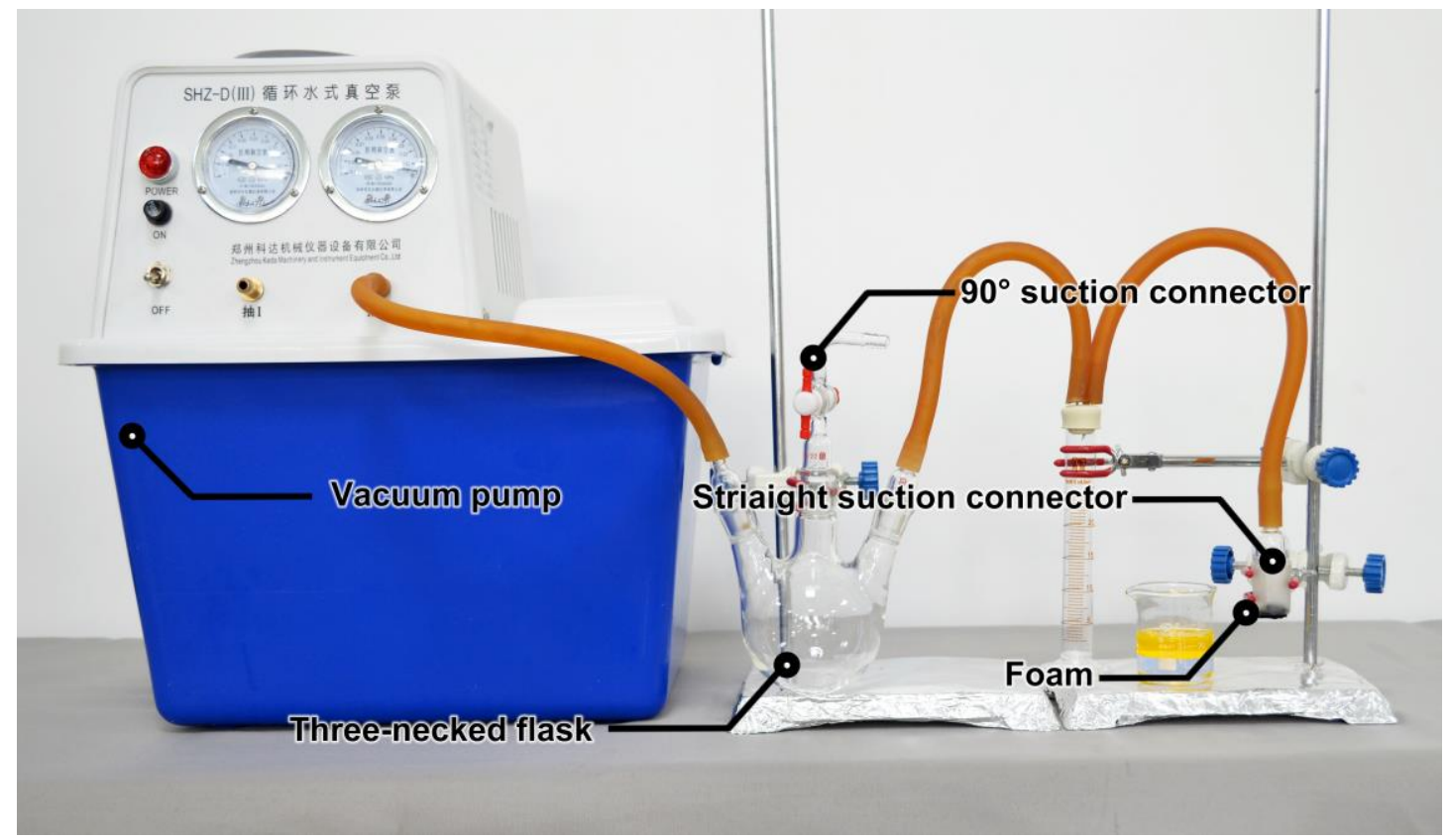

Figure S19. Photo image of the device used to remove oil from water surface. 
(a)

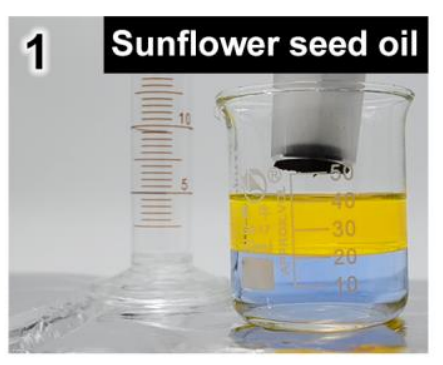

(b)

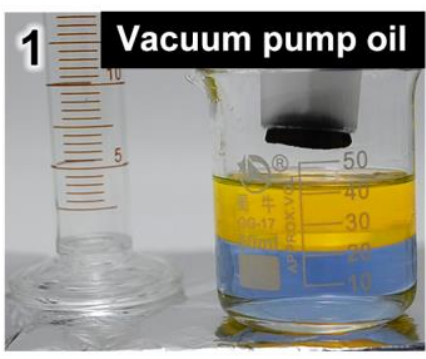

\section{$9.5 \mathrm{~min}$}
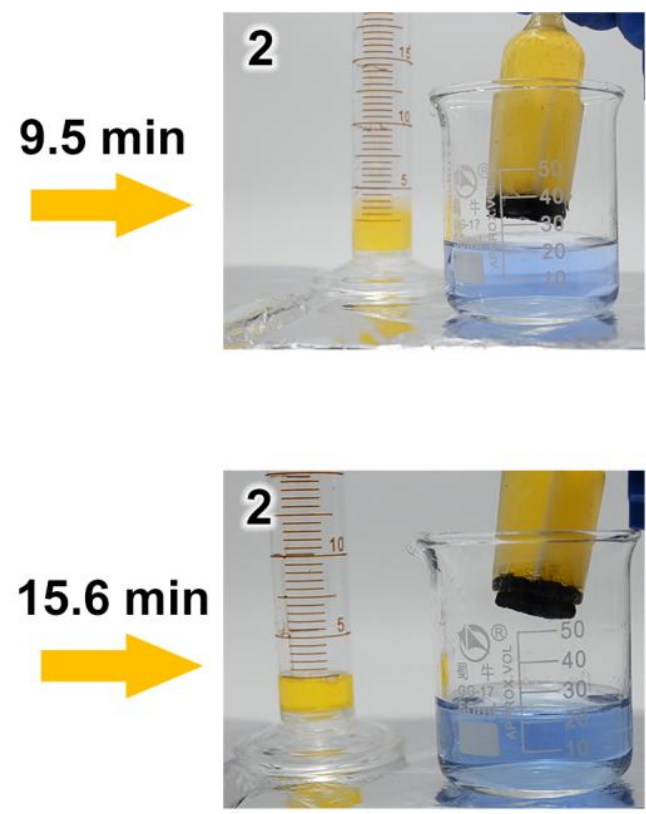

Figure S20. Time-sequence images of using the MCNTs/PDMS-PUa foams to remove (a) sunflower seed oil and (b) pump oil from water.

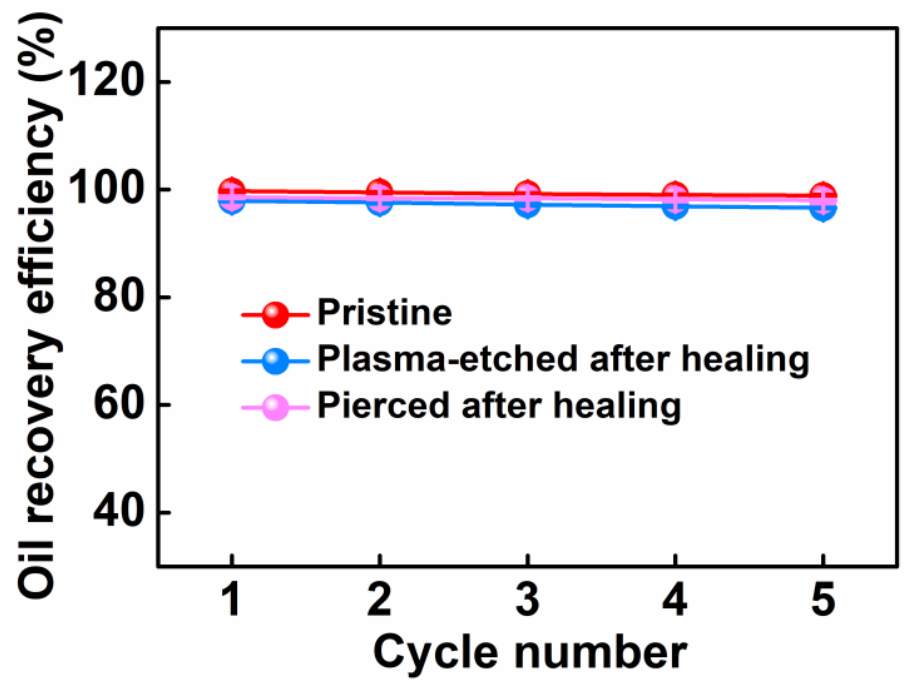

Figure S21. Oil recovery efficiency of the pristine MCNTs/PDMS-PUa foam and healed MCNTs/PDMS-PUa foams (plasma-etched and pierced) after different cycles of removing $20 \mathrm{~mL}$ of gasoline from water. 


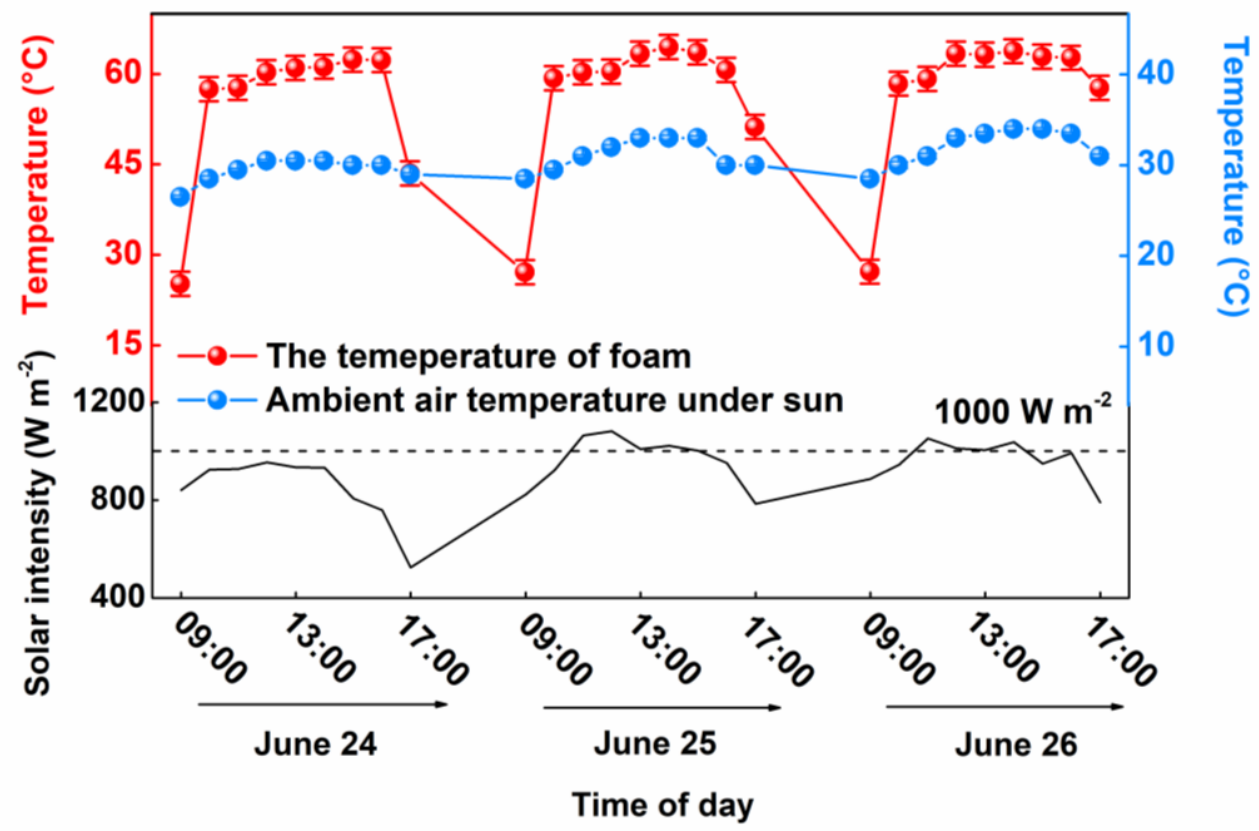

Figure S22. The solar intensity, ambient temperature, and temperature changes of the pierced MCNTs/PDMS-PUa foam under the sun at Jilin University.

\section{REFERENCES}

(1) Gao, S. W.; Dong, X. L.; Huang, J. Y.; Dong, J. N.; Cheng, Y.; Chen, Z.; Lai, Y. K. Co-solvent Induced Self-Roughness Superhydrophobic Coatings with Self-Healing Property for Versatile Oil-Water Separation. Appl. Surf. Sci. 2018, 459, 512-519.

(2) Long, M.; Peng, S.; Deng, W.; Yang, X.; Miao, K.; Wen, N.; Miao, X.; Deng, W. Robust and Thermal-Healing Superhydrophobic Surfaces by Spin-Coating of Polydimethylsiloxane. J. Colloid. Interf. Sci. 2017, 508, 18-27.

(3) Peng, S.; Meng, W.; Guo, J.; Wang, B.; Wang, Z.; Xu, N.; Li, X.; Wang, J.; Xu, J. Photocatalytically Stable Superhydrophobic and Translucent Coatings Generated from PDMS-Grafted-SiO $2 / \mathrm{TiO}_{2} @$ PDMS with Multiple Applications. Langmuir 2019, 35, 2760-2771.

(4) Zhang, X. Y.; Xu, L. H.; Shen, Y.; Wang, L. M.; Ding, Y. One-Step Fabrication of Self-Healing and Durable Superhydrophobic Cotton Fabrics Based on Silica Aerogel. J. Nanosci. Nanotechno. 2018, 18, 7721-7731.

(5) Chen, K. L.; Gou, W. W.; Xu, L.; Zhao, Y. Low Cost and Facile Preparation of Robust Multifunctional Coatings with Self-Healing Superhydrophobicity and High Conductivity. Compos. Sci. Technol. 2018, 156, 177-185.

(6) Tu, K. K.; Wang, X. Q.; Kong, L. Z.; Guan, H. Facile Preparation of Mechanically Durable, Self-Healing and Multifunctional Superhydrophobic Surfaces on Solid Wood. Mater. Design 2018, 140, 30-36.

(7) Liu, Y.; Liu, J.; Tian, Y.; Zhang, H.; Wang, R.; Zhang, B.; Zhang, H.; Zhang, Q. 
Robust Organic-Inorganic Composite Films with Multifunctional Properties of Superhydrophobicity, Self-Healing, and Drag Reduction. Ind. Eng. Chem. Res. 2019, 58, 4468-4478.

(8) Qin, L. M.; Chen, N.; Zhou, X.; Pan, Q. M. A Superhydrophobic Aerogel with Robust Self-Healability. J. Mater. Chem. A 2018, 6, 4424-4431. 